\title{
РОЛЬ АНТИОКСИДАНТНЫХ ФЕРМЕНТОВ В КОНДЕНСАТЕ ВЫДЫХАЕМОГО ВОЗДУХА ПРИ ХРОНИЧЕСКОЙ БОЛЕЗНИ ЛЕГКИХ У БОЛЬНЫХ ВЛАДИМИРСКОЙ ОБЛАСТИ
}

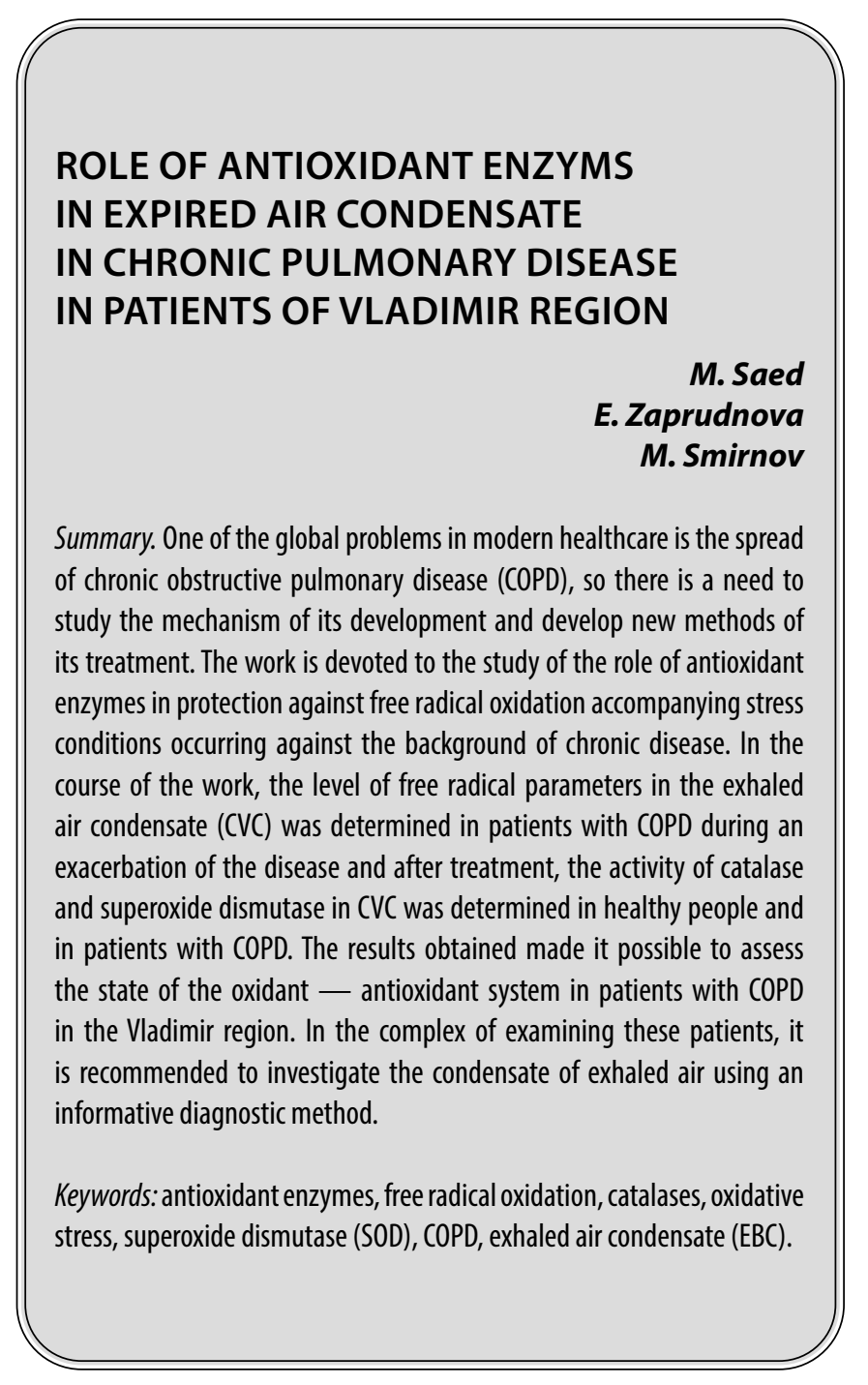

\section{Введение}

B о всем мире хроническая обструктивная болезнь легких (ХОБЛ) является проблемой здравоохранения с серьезными экономическими и социальными последствиями, поэтому поиск методов диагностики и лечения данного заболевания является чрезвычайно актуальным.

Около 90\% пациентов с ХОБЛ - курильщики, табачный дым сам по себе является мощным источником оксидантов. Совершенствование методов диагностики

\author{
Саед Манас \\ Аспирант, Владимирский Государственный \\ университет \\ Manas.saed@gmail.com \\ Запруднова Елена Александровна \\ К.б.н., доцент, Владимирский Государственный \\ университет \\ eazaprudnova@mail.ru \\ Смирнов Михаил Владимирович \\ ГБУз Владимирской Области «Областная \\ Клиническая Больнича» \\ msmirnovsl@gmail.com
}

Аннотация. Одной из глобальных проблем в современном здравоохранении является распространение хронической обструктивной болезни легких (ХОБЛ), поэтому существует необходимость изучения механизма ее развития и разработки новых методов ее лечения. Работа посвящена изучению роли антиоксидантных ферментов в защите от свободнорадикального окисления, сопровождающего стрессовые состояния, протекающие на фоне хронического заболевания. В ходе работы был определен уровень свободнорадикальных показателей в конденсате выдыхаемого воздуха (КВВ) у больных ХОБЛ во время обострения заболевания и после лечения, определена активность каталазы и супероксиддисмутазы в КВВ у здоровых людей и у больных ХОБЛ. Полученные результаты позволили оценить состояние системы оксиданты - антиоксиданты у больных ХОБЛ Владимирской области. В комплексе обследования данных больных рекомендуется исследовать конденсат выдыхаемого воздуха с помощью информативного диагностического метода.

Ключевые слова: антиоксидантные ферменты, свободнорадикальное окисление, каталазы, оксидативный стресс, супероксиддисмутазы (СОД), ХОБЛ, конденсат выдыхаемого воздуха (КВВ).

и терапии ХОБЛ является одной из наиболее сложных задач современной пульмонологии [13, С. 129].

Хроническая обструктивная болезнь легких (ХОБЛ) характеризуется частичным необратимым, с прогрессирующим характером прохождением воздуха в дыхательной системе, что объясняется аномальной воспалительной реакцией ткани легких на раздражение различными патогенными частицами и газами.

На слизистую бронхов при воздействии патогенных факторов изменяются функции гиперсекреции слизи 
и секретов бронхов. При этом происходит присоединение инфекций и реакций, повреждающих бронхиол, альвеол и антиоксидантной защиты легких, что нарушает соотношение протеолитических ферментов и антипротеаз.

Основные критерии диагностики[7, С. 132]:

- кашель, мокрота, одышка - клинические критерии;

- появляются факторы риска - анамнестические критерии;

- функциональные критерии - снижаются показатели: объема форсированного выдоха за 1 секунду (ОФВ1) до менее 80\% после ингаляции бронходилататора, чувствительного индекса снижения проходимости дыхательных путей (индекса Тиффно) - соотношения ОФВ1/ФЖЕЛ до менее $70 \%$ проявления.

Вследствие ХОБЛ ограничивается физическая работоспособность, что ведет к инвалидности пациентов.

Виды ХОБЛ: хронический обструктивный бронхит, эмфизема легких, тяжелые формы бронхиальной астмы, хронический облитерирующий бронхиолит, бронхоэктатическая болезнь, муковисцидоз, биссиноз.

Факторы риска ХОБЛ [3, С. 58]:

1. Внешние факторы:

- курение, наличие в воздухе кадмия и кремния (профессиональные);

- пассивное курение детей;

- загрязнение воздуха газами SO2, NO2, O3;

- аденовирусная инфекция, дефицит витамина С.

2. Внутренние факторы:

- дефицит в организме производимого печенью белка - а1-антитрипсина, который участвует с помощью инактивации ферментов в защите легких от панкреатической эластазы;

- недоношенность ребенка, наследственность;

- высокий уровень иммуноглобулина Е (IgE) в сыворотке крови и секретах;

- бронхиальная гиперреактивность;

- генетическая предрасположенность (группа крови A(II), отсутствие иммуноглобулина A $(\lg A)$.

В механизме появления и развития ХОБЛ (в патогенезе) имеют основное значение воспалительные и окислительные стрессы, дисбаланс протеиназ и антипротеиназ в легких, что разрушает легкие и дыхательные пути и происходят необратимые патологии.

Рассмотрим цели лечения ХОБЛ[4, С. 76]:

- предупреждение и терапия осложнений при лечении;
- облегчение симптомов болезни;

- обеспечение физической активности;

- снижение смертности.

В настоящее время анализ конденсата выдыхаемого воздуха (KВВ) - это область для активных исследований легочной патологии, так как является безопасным, неинвазивным, экономически доступным методом, не оказывает влияния на состав получаемого образца и функцию легких, не повреждает слизистую респираторного тракта, прост в выполнении и является высокоинформативным[5, С. 220].

Целью настоящей работы является изучение влияния антиоксидантных ферментов в КВВ у больных ХОБЛ Владимирской области.

\section{Материалы и метолы исслеАования}

В эксперименте принимали участие пациенты пульмонологического отделения Владимирской областной клинической больницы, страдающие хронической обструктивной болезнью легких, находящиеся на лечении по причине обострения заболевания, и на кафедре биологии и экологии.

Три группы: группа здоровых (некурящих) пациентов, группа пациентов с ХОБЛ до начала лечения, группа пациентов с ХОБЛ после лечения. Все пациенты - мужчины, возраст 63.4 лет, стаж курения 38.5 лет, срок болезни 7.5 лет.

Изучение показателей свободнорадикального окисления проводилось с использованием КBВ, который сам по себе не оказывает влияния на собираемые образцы.

Диагноз заболевания устанавливали согласно протоколам (стандартам) диагностики и лечения больных с ХОБЛ (Федеральная программа «Хроническая обструктивная болезнь легких», 2004) в соответствии с Международной классификацией болезней 10 пересмотра и Глобальная инициатива по хронической обструктивной болезни легких (Global initiative for chronic obstructive lung disease (GOLD Workshop Report 2006).)

Содержание нитратов/нитритов в КВВ определялось по методу Грисса с использованием редуктора нитратов.

Метод определения малонового диальдегида основан на реакции МДА с тиобарбитуровой кислотой. Антиоксидантная активность супероксиддисмутазы определялась по методу Сироты Т.В. Определение активности каталазы осуществлялось по методу Баха и Зубковой. 
Концентрация NO3-NO2- , мкмоль/л

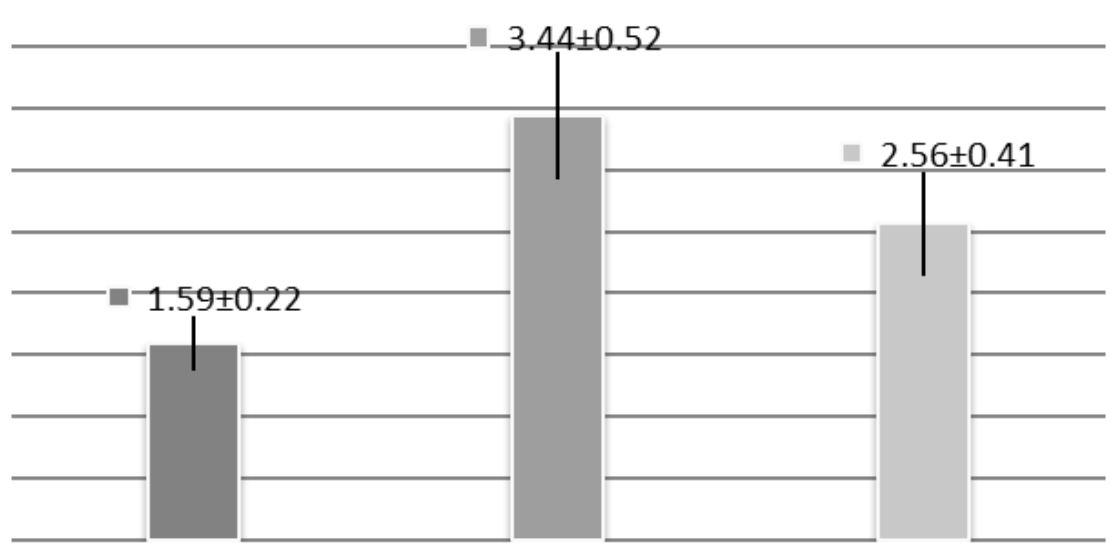

1.Контрольная группа здоровых людей.

Группы

2. Концентрация нитратов/нитритов во время обострения.

3. После лечения.

Рис. 1. Содержания нитратов/нитритов при лечении пациентов с ХОБЛ

Концентрация МДА,МКМОЛЬ/Л

$0.23 \pm 0.014$

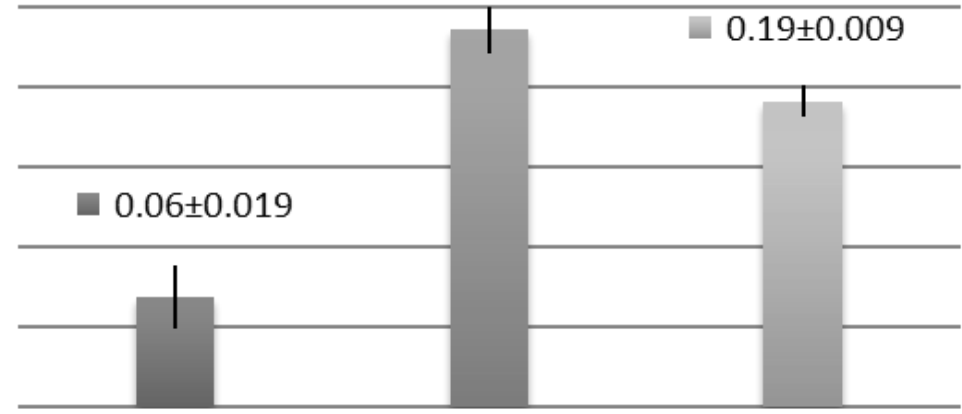

1.Контрольная группаздоровых людей.

Группы

2. Концентрация малонового диальдегида во время обострения.

3. После лечения.

Рис. 2. Содержание малонового диальдегида при лечении пациентов с ХОБЛ

Результаты исслеАования

и их обсужАение

Одной из главных задач работы была оценка динамики изменения показателей нитратов и нитритов в КВВ у больных ХОБЛ при обострении заболевания.
На рисунке 1 показаны содержания нитратов/нитритов при лечении пациентов с ХОБЛ.

Установлено, что в результате обострения ХОБЛ происходит увеличение суммарной концентрации нитратов/нитритов во время обострения в 2.16 раз $(\mathrm{P}<0,05$ 


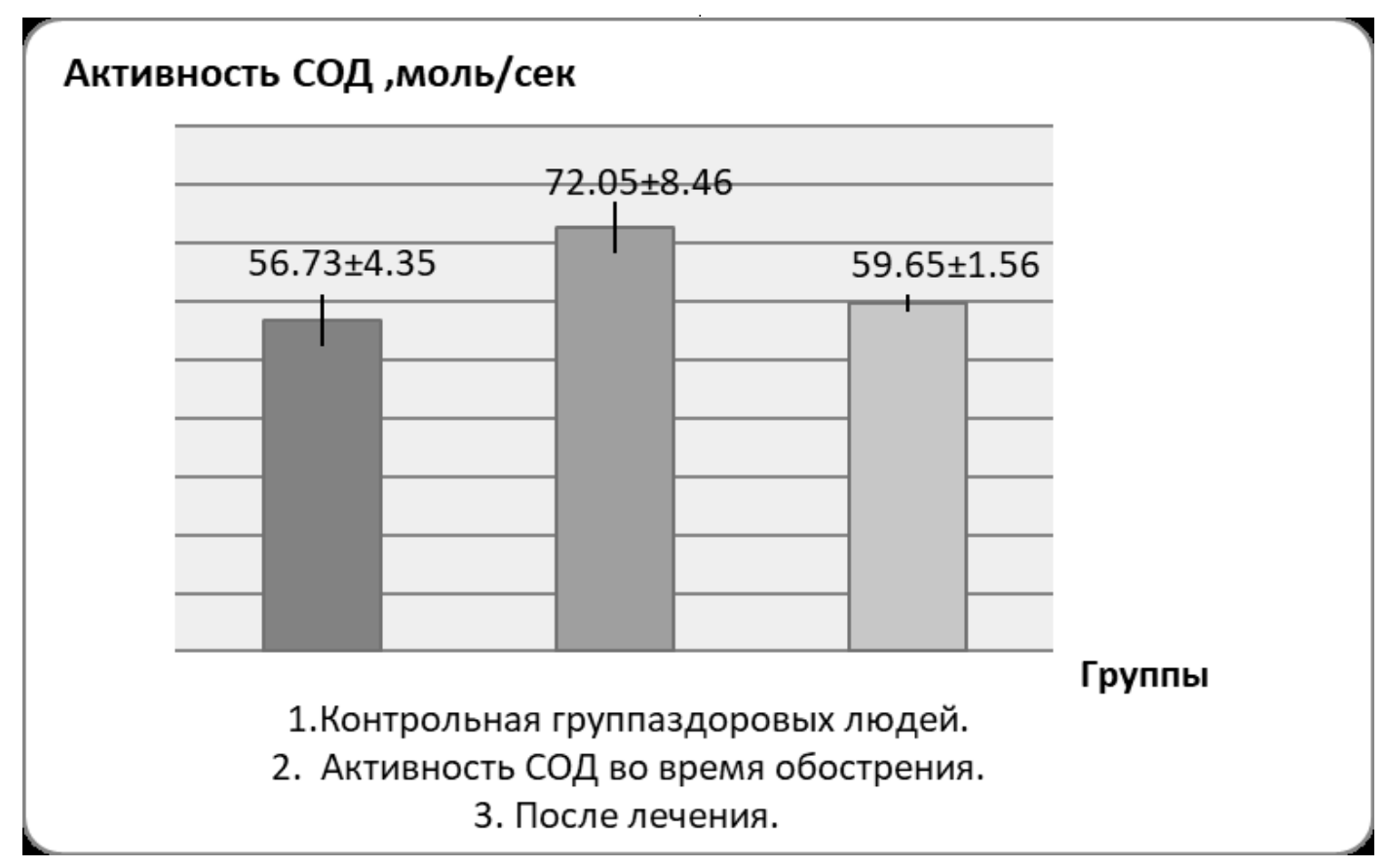

Рис. 3. Активность СОД при лечении пациентов с ХОБЛ

по сравнению с контрольной группой), которое остается высоким и после лечения в 1.61 раз по сравнению с контрольной группой практически здоровых людей. $(\mathrm{P}<0,05)$.

Концентрация нитратов/нитритов В КВВ во время обострения у пациентов ХОБЛ в 1.34 раза больше, чем в КВВ после лечения.

Для более полной оценки свободнорадикального статуса испытуемых было проведено так же определение динамики изменения показателей малонового диальдегида в конденсате выдыхаемого воздуха.

На рисунке 2 показано содержание малонового диальдегида при лечении пациентов с ХОБЛ.

Установлено, что в результате обострения ХОБЛ происходит увеличение суммарной концентрации МДА во время обострения в 3.83 раза ( $<<0,05$ по сравнению с контрольной группой), которое остается высоким и после лечения в 3.16 раз по сравнению с контрольной группой практически здоровых людей $(p<0,05)$.

Концентрация малонового диальдегида в КВВ во время обострения у пациентов ХОБЛ в 1.21 раз больше, чем в КВB после лечения.

Можно сделать вывод о том, что существуют различия между показателями содержания малонового диальдегида во время обострения и после лечения.
Рассмотрим активность супероксиддисмутазы в КВВ у здоровых людей и больных ХОБЛ.

Во всех аэробных клетках в процессе присоединения одного электрона к молекуле кислорода образуются супероксидный анион-радикал $-\mathrm{O}_{2}$ и и его протонированная форма - гидроперекисный радикал - $\mathrm{HO}_{2}{ }^{*}$. Они оба порождают ряд других активных форм кислорода.

В качестве регуляторов образования АФК выступают антиоксиданты, среди которых антиоксидантные ферменты - супероксиддисмутаза и каталаза.

На рисунке 3 показана активность супероксиддисмутазы (СОД) эритроцитов при лечении пациентов с ХОБЛ.

При обострении также возрастает активность СОД по сравнению с контрольной группой в 1.23 раза $(\mathrm{P}<0,05)$. Однако, следует отметить, что интенсификация свободнорадикальных показателей происходит в большей степени.

После лечения активность СОД лишь незначительно превышает показатели контрольной группы (в 1.05 раз больше по сравнению с контрольной группой практически здоровых людей, $\mathrm{P}<0,05)$. При этом активность СОД в КВВ во время обострения у пациентов с ХОБЛ в 1.20 раз больше, чем в КВВ после лечения.

Рассмотрим активность каталазы в КВВ у здоровых людей и больных ХОБЛ. 
Активность каталазы ,мкмоль/мин.

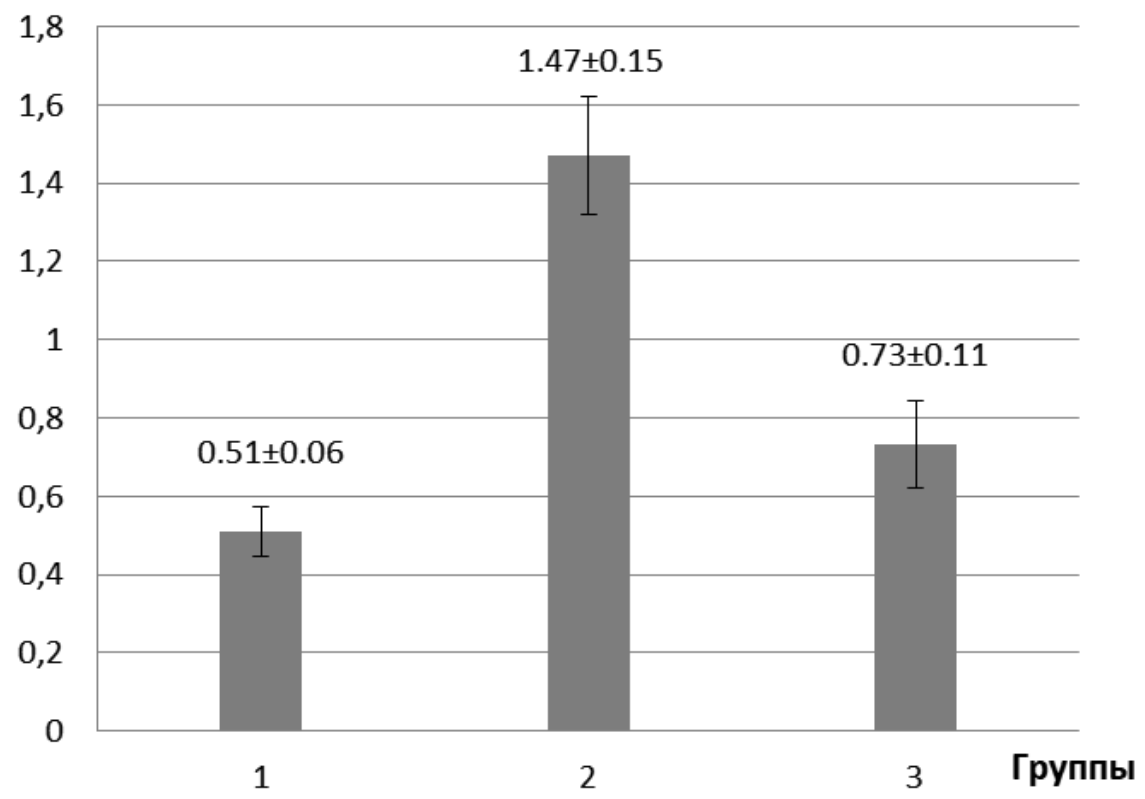

1.Контрольная группа здоровых людей.

2. Активность каталаз во время обострения.

3. После лечения.

Рис. 4. Активность каталазы при лечении пациентов с ХОБЛ

Фермент каталаза содержится в большом количестве в эритроцитах, а также во всех тканях и жидкостях организма. Биологическая роль каталазы заключается в обезвреживании пероксида водорода $\left(\mathrm{H}_{2} \mathrm{O}_{2}\right)$ путем его разложения на молекулярный кислород и воду:

$$
2 \mathrm{H}_{2} \mathrm{O}_{2} \rightarrow \mathrm{O}_{2}+2^{*} \mathrm{H}_{2} \mathrm{O}
$$

На рисунке 4 показана активность каталазы при лечении пациентов с ХОБЛ.

Во время обострения ХОБЛ у пациентов, наряду с интенсификацией свободнорадикального окисления происходит значительное увеличение активности каталазы в 2.88 раза ( $p<0,05$ по сравнению с контрольной группой).

После лечения активность каталазы в 1.43 раза остается выше показателя здоровых людей ( $p<0,05$ по сравнению с контрольной группой). Активность каталазы В КВВ во время обострения у пациентов ХОБЛ в 2.01 раз больше, чем в КВВ после лечения.

\section{Выво $\triangle \mathrm{b}$}

1. ХОБЛ сопровождается увеличенным образования свободных радикалов (NO и МДА), что отражается в увеличении показателей нитратов/нитритов в 2.16 раз $(\mathrm{P}<0,05)$ и МДА в 3.83 раза $(\mathrm{P}<0,05)$ как при обострении заболевания, так и после лечения эти показатели оказываются выше показателей здоровых людей нитраты/ нитриты в 2.16 раз, МДА в 3.16 раз $(\mathrm{P}<0,05)$.

2. Антиоксидантная система (ферменты каталаза и СОД) активизируется в ответ на рост количества свободных радикалов при ХОБЛ.

Активность каталазы увеличивается при обострении в 2.88 раз $(\mathrm{P}<0,05)$, а активность СОД в 1.23 раза $(\mathrm{P}<0,05)$.

Активность антиоксидантных ферментов поддерживается на большем уровне, по сравнению со здоровыми испытуемыми и после лечения СОД в 1.05 раз и каталазы в 1.43 раза $(\mathrm{P}<0,05)$.

3. Увеличение активности СОД происходит в недостаточной степени по сравнению с интенсификацией оксидантных процессов. Активность СОД в КВВ во время обострения у пациентов ХОБЛ увеличивается лишь в 1.23 раза по сравнению с контрольной группой практически здоровых людей, в то время как свободнорадикальные показатели возрастают нитраты /нитриты в 2.16 раз и МДА в 3.83 раза. Это свидетельствует о недостаточ- 
ности антиоксидантной защиты у пациентов с хроническим заболеванием.

Анализ выдыхаемого воздуха - новый перспективный метод диагностики различных заболеваний. Состав выдыхаемого воздуха различен в норме и при патологии. Современное развитие технологий позволяет пере- нести анализ выдыхаемого воздуха из научно-исследовательских лабораторий в клиническую практику. Таким образом, в арсенале врачей появился новый инструмент проведения анализа активности антиоксидантных ферментов в защите от свободнорадикального окисления, сопровождающего стрессовые состояния, протекающие на фоне хронического заболевания.

\section{ЛИТЕРАТУРА}

1. Агеева Т.С, Букреева Е. Б. Внутрибольничная эндобронхиальная суперинфекция у больных неспецифическими воспалительными заболеваниями легких // Материалы юбилейной конференции, посвященной 200-летию Российской Военно-медицинской академии. Томск. 1999. С. 324-336.

2. Аболин Л. М. Психологические механизмы эмоциональной устойчивости. Казань: Изд-во Казан. ун-та, 1987. 261 с.

3. Будневский А.В., Цветикова Л. Н., Овсянников Е. С., Гончаренко О. В. Мелатонин: роль в развитии хронической обструктивной болезни легких // Пульмонология. 2016. № 26 (3). С. 372-378. D0l: https://doi.org/10.18093/0869-0189-2016-26-3-372-378

4. Букреева Е.Б., Агеева Т. С. Материалы I Всесоюзного конгресса по болезням органов дыхания // Эндобронхиальная суперинфекция у больных неспецифическими воспалительными заболеваниями легких.Киев, 1990. № 960.

5. Быкова А.А., Малиновская Л. К., Чомахидзе П. Ш., Трушина О. В., Шалтаева Ю. Р., Беляков В. В., Головин А. В., Першенков В. С., Сыркин А. Л., Бетелин В. Б., Копылов Ф. Ю. Анализ выдыхаемого воздуха в диагностике сердечно-сосудистых заболеваний // Кардиология. 2019. № 59 (7). C. 61-67. D0l: https://doi. org/10.18087/cardio.2019.7.10263

6. Пирогов А.Б., Нахамчен Л. Г., Приходько А. Г., Перельман Ю. М., Бородин Е. А., Зиновьев С. В. Роль эозинофильного компонента воспаления бронхов и перекисного окисления липидов в формировании реакции дыхательных путей на физическую нагрузку у больных бронхиальной астмой // Бюллетень физиологии и патологии дыхания. 2017. № 63. C. 8-15. D0l: https://doi.org/10.12737/article_58e18e117d1b54.28286598

7. Шмелев Е. И. Хроническая обструктивная болезнь легких. М., 2003.

8. Щербатых Ю. В. Экзаменационный стресс. Воронеж: (тудия ИАН, 2000. 120 c.

9. Andenaes R., Moum T., Kalfoss M. H. et al. Changes in health status, psychological distress, and quality of life in COPD patients after hospitalization // Qual Life Res. 2006. № 15. C. 249-257.

10. Eisner M.D., Blanc P. D., Yelin E. H. et al. Influence of anxiety on health outcomes in COPD // Thorax. 2010. № 65. C. $229-234$.

11. Gavura S. Antioxidants and Exercise: More Harm Than Good? // Science Based Medicine. Retrieved 19 December 2011.

12. Halliwell B. Antioxidant defense mechanisms: from the beginning to the end (of the beginning) // Free Radical Research. 1999. № 31. Pp. $261-272$.

13. Сервис регистрации доменов и хостинга. Режим доступа: www.tass-ural.ru.

с Саед Манас ( Manas.saed@gmail.com ), Запруднова Елена Александровна ( eazaprudnova@mail.ru ),

Смирнов Михаил Владимирович ( msmirnovsl@gmail.com ).

Журнал «Современная наука: актуальные проблемы теории и практики» 